\title{
Disaster Documentation Revisited
}

\author{
The Evolving Damage Assessments of Emergency Management in Oregon \\ Henry A. Covey \\ Professional \& Technical Communication, Portland State University, USA \\ covey@pdx.edu
}

\begin{abstract}
This report revisits a previous case study focused on the computing machinery and design of communication that are employed at the local, county, regional, state, and federal levels in Oregon to collect, review, and publish damage assessments of disasters and other emergency events. Since the last report, emergency managers throughout Oregon have faced numerous disaster incidents, including the COVID-19 pandemic, ice storms, flooding, and some of the worst heat waves, drought conditions, and megafires on record, with the threat of more to come in the years ahead. After years of research and development, fueled by lessons learned from a catastrophic wildfire season, a new generation of damage assessment tools and shared services has been pushed to the fore, ones which integrate geographic information systems and relational spatial databases not only to help assess damage but also automate and coordinate workflows. This revisitation explores the urgency and impetus for change and analyzes the Oregon Damage Assessment Project, a statewide initiative of the Office of Emergency Management to standardize shared tools and services for government agencies, partner organizations, and the public at large.
\end{abstract}

\section{CCS CONCEPTS}

- Applied computing $\rightarrow$ Enterprise computing; Enterprise information systems; Enterprise applications; • Information systems $\rightarrow$ Information systems applications; Spatial-temporal systems; Geographic information systems; • Human-centered computing $\rightarrow$ Visualization; Visualization application domains; Geographic visualization.

\section{KEYWORDS}

Technical communication, disaster declaration, damage assessment, emergency management, climate change, XLSForm, FEMA, Esri

\section{ACM Reference Format:}

Henry A. Covey. 2021. Disaster Documentation Revisited: The Evolving Damage Assessments of Emergency Management in Oregon. In The 39th ACM International Conference on Design of Communication (SIGDOC '21), October 12-14, 2021, Virtual Event, USA. ACM, New York, NY, USA, 15 pages. https://doi.org/10.1145/3472714.3473625

Permission to make digital or hard copies of all or part of this work for personal or classroom use is granted without fee provided that copies are not made or distributed for profit or commercial advantage and that copies bear this notice and the full citation on the first page. Copyrights for components of this work owned by others than the author(s) must be honored. Abstracting with credit is permitted. To copy otherwise, or republish, to post on servers or to redistribute to lists, requires prior specific permission and/or a fee. Request permissions from permissions@acm.org.

SIGDOC '21, October 12-14, 2021, Virtual Event, USA

(C) 2021 Copyright held by the owner/author(s). Publication rights licensed to ACM. ACM ISBN 978-1-4503-8628-9/21/10 . \$ \$15.00

https://doi.org/10.1145/3472714.3473625

\section{INTRODUCTION: THE EVOLVING TECHNOLOGY OF DAMAGE ASSESSMENTS}

Damage assessments are communication tools that governments of all levels - local, regional, national, and international - use to collect, review, and publish emergent data and information about a disaster event and other emergencies.

Viewed along the time and space of an event, damage assessments are typically short-lived workflows, explosions of print and digital documentation about the emergency's impact that spring from the event and serve as a source of information (text) and data (numbers, symbols, charts, graphs, etc.), which in turn helps guide the allocation of aid to individuals, businesses, and local governments in need. In the end, damage assessments become the repositories of finalized documentation about that event, artifacts to be archived and used with regard to the future, ideally, to create institutional knowledge and wisdom about planning for and facing the next event.

From a social-rhetorical standpoint, damage assessments are highly collaborative, multipurpose documents. They are created for an assortment of individuals and groups, each with a different role and unique spatial-temporal relationship to the event, to the other individuals and groups also in the space and time of the event, and to the nonhuman actors employed to compute damage assessment data and information, i.e., computing machinery.

In a disaster event, the sheer number of people and increased level of complexity underlies the importance of a damage assessment's successful design of communication. However, ensuring a repeatedly coordinated statewide response during emergencies is a wicked problem that the complexity of the damage assessment activity can help or hinder. At their best, damage assessments are freely flowing nexuses of informative data and updating information embedded in a clockwork-like workflow; at their worst, damage assessments are data silos and bottlenecks of paperwork that strangle time-sensitive workflows with time-intensive data sifts, sucking the oxygen and energy away from other response and recovery activities. Sometimes, the damage assessment's design of communication becomes its own wicked problem, and the data-gathering, analysis, and/or publication process remains mired in legacy technology, or a declaration report process does not go as smoothly as desired, or it undermines some hoped-for outcome.

The previous "disaster documentation" report analyzed the damage assessment approach used by the State of Oregon's Office of Emergency Management (OEM) in orchestration with more than a hundred local emergency managers across thirty-six counties [1]. Mapping the authoring process and publication circuits revealed an evolving disaster assessment software methodology, not only in Oregon but also nationally, one that is also more in tune with federal requirements and shared objectives. The report ended with 
a look ahead, touching on the potential benefits of integrating geographic information systems (GIS) to assist the process (e.g., Esri's Survey123 platform, part of ArcGIS Online), which is where this report picks up.

Much has happened since the fall 2019 SIGDOC conference. OEM and local emergency managers across Oregon's 36 counties (and those worldwide) have been kept busy by the global pandemic, not to mention numerous local emergencies. Then, in the summer of 2020, persistent drought and high temperatures in Oregon gave way to epic wildfires driven by coastal straight-line winds that ravaged through multiple counties. On the heels of the devastation, the wildfires still fresh in Oregonians' minds, with officials anticipating more summers of the same to come (which have), the Oregon Damage Assessment Project emerged, an initiative grown from years of research and development to integrate spatial data infrastructure, tools, and services into the existing statewide damage assessment methodology and workflows. The project represents an evolution in how damage assessments are generated in Oregon, where standardized content creation tools and geospatial content management systems are now helping to support individuals, businesses, and local governments involved in an emergency event (guiding new and returning users, visualizing emergent data, anticipating and automating computing tasks, etc.) - which has thus far been a design-of-communication task/job that has been reserved for common word-processing documents, macro-enabled spreadsheet forms and surveys, and static presentation and training slides, all hyperlinked on public-facing webpage.

This report looks at what has changed at the statewide-to-local levels and how the damage assessment technology and methodology have evolved, including a brief review of the current state, the impetus for technological metamorphosis, and an analysis and discussion of the Oregon Damage Assessment Project, including its website, public-facing documentation, and ongoing development.

\section{RESEARCH: REVISITING LOCAL \& STATE EMERGENCY MANAGEMENT}

This follow-on report started in the pandemic with a revisitation of the official OEM webpage (URL below) to reassess and review the links to the current state damage assessment forms, templates, and resources used by emergency managers and other officials during a disaster declaration, the "Damage Assessment Forms, Templates \& Resources" page on the OEM website [2].

- https://www.oregon.gov/oem/emresources/disasterassist/ Pages/Damage-Assessment.aspx

On this webpage, a local emergency manager at the county, regional, city, municipal, tribal, or other jurisdictional level, as well as anyone in the public, can click on hyperlinks to download files used to train people, assess emergencies, and report damage data and information to OEM, which is then compiled into summary reports for FEMA. Content on the webpage includes damage assessment documentation for all phases of the process - from the "quick capture" rapid damage assessment (RDA) that is made ASAP after the event, to the "initial" damage assessment (IDA) made by counties and partners with the state, to the "preliminary" damage assessment (PDA) completed by FEMA with state and local officials.
This includes documentation for all the types of assistance: individual assistance (IA), small business association (SBA) assistance, and public assistance (PA).

After a review of the hyperlinks provided on Oregon.gov's Damage-Assessment.aspx webpage, not a lot had changed on the page or has since after rechecking; files are the same 2016 versions that were reviewed in the previous report: legacy spreadsheets embedded with macros for collecting and computing damage (.xls), desktop training manuals (.doc and .pdf) without enhanced navigation (e.g., hyperlinked headings) or updated accessibility standards (e.g., alternative text), and PowerPoint slides as training material (.ppt exported to .pdf).

To learn more about the latest developments of damage assessments for this report, OEM and local emergency managers across thirty-six counties of Oregon were emailed for more information on any updates to their tools or processes for statewide assessments. Each was provided with a short introduction to the research project and a series of initial questions about the set of forms and documents on the OEM website (the "Damage Assessment Forms, Templates and Resources" URL above and hyperlinks to the IDA data collection form, county summary, and PDA summary form below), including:

- https://www.oregon.gov/OEM/Documents/IDA_Data_ Collection_Form_Public_Infrastructure.xls

- https://www.oregon.gov/OEM/Documents/IDA_County_ Summary_Form.xls

- https://www.oregon.gov/OEM/Documents/PDA_Form. xlsx

Survey questions included:

- How do you collect data for rapid and/or initial damage assessments?

- What information systems do you use to collect rapid/initial data?

- What has been your experience using the forms listed above?

- Do you have thoughts, ideas, or opinions about these forms?

- Other than the above, what questions should I be asking?

- Would you be interested in talking further about this?

The survey response rate was close to 15 percent $(n=21 / 145)$, which resulted in several referrals, strings of email correspondence with local emergency managers, and two hour-long interviews, one by phone and the other via video conferencing and screen-sharing. Reponses came from emergency officials in jurisdictions large and small. Some local emergency managers provided perspective on being affected by the 2020 wildfires. Others provided user feedback on the legacy Microsoft Office files currently in use. Many emergency managers spoke of the 2020 wildfires, and some pointed to OEM for further contact about new initiatives at the state level. OEM provided clarity beyond the initial set of questions above on the state's current GIS program coordination and methodology. Below are the results of these conversations, correspondence, and further research on Oregon's evolving statewide damage assessment methodology, tool, and services. 


\section{USE-CASE SCENARIO: HIGH WINDS, WILDFIRES \& FIREWALLS}

On September 7, 2020, after continued critically hot and dry conditions, numerous fires ignited and spread dramatically throughout many local emergency management jurisdictions during multiple days of sustained tropical-storm-force straight-line winds (average 20-30 mph with 50-60 mph gusts). Of the twenty-plus fires that started, the Archie Creek, Holiday Farm, and Riverside complexes grew into megafires $(100,000+$ acres $)$. Multiple cities and towns were affected, and massive damage was incurred to homes, businesses, and public structures, including roads. Interstate 5, Highway 22, and Highway 101 were among many major local arteries and throughways that were closed for multiple miles due to hazards and debris in the area, all requiring cleanup. Over the course of the event, around 500,000 Oregonians were put under some form of evacuation notice (level 1, 2 or 3), and more than 40,000 were forced to evacuate [3]. Thousands of residents of densely populated areas got caught in bumper-to-bumper traffic trying to flee, like in the city of Medford and other municipalities [4]. Many people did not receive a local emergency alert [5]. Some in Marion County survived the night by wading into rivers and creeks, and dozens were led in a convoy out of Detroit, Oregon, in a dramatic last-minute rescue after helicopters were unable to land and evacuate them [6]. Those not given an evacuation order also experienced substantial smoke and hazardous air quality. Air quality measurements in affected counties were at times worse than the most hazardous air classifications currently available, and much of the state lay under a blanket haze of smoke during the event. In the end, Oregon's catastrophic 2020 fire season killed nine people, burned over one million acres across the state (twice the ten-year average), cost hundreds of millions in public damages $(\$ 380,228,948)$, and destroyed thousands of homes (4,070 destroyed, 54 damaged). The total dollars of estimated damage topped \$100M (individual household, \$37M; public assistance, $\$ 6.7 \mathrm{M}$; and small business, $\$ 60.6 \mathrm{M}$ ) [3].

All of the above is known because of local news reporting but also because of the technical report work put into various sets of damage assessments completed and compiled by local and state emergency management operations and partners throughout the state during after the event. The state used damage assessment reports to request a federal declaration for individual assistance (Category B, emergency protective measures) for eight counties in Oregon (Clackamas, Douglas, Jackson, Klamath, Lane, Lincoln, Linn, and Marion), as well as a request for direct federal assistance under the Public Assistance program for twenty-four counties and hazardous mitigation statewide [7]. Of the eight counties involved with the Individual Assistance federal declaration, only two used the common FEMA schema, and not all data and information came in at the same time, while some datasets were found to be incomplete or not maintained, and in some cases, datasets were difficult to obtain or were not available, causing repetitive asks for the same data and information within the same jurisdiction multiple times (e.g., tax lot data), and there was a general lack of coordination between the local fire agencies and the incident command post [8]. It took approximately two weeks to complete an official assessment of the number of homes that had been destroyed. At a certain point, it became clear that of the lessons learned in the fallout of the historic catastrophe of the 2020 fires, as it related to damage assessments, the importance of coordinating data standardization of authoritative sources topped the list.

Authoritative data sources are hard enough to wrangle during an emergency. Not all the authoritative data and information come in at the same time, and data accuracy and sources can also change during the course of an event. There can be many layers of data per county with more than one agency or partner organization making overlapping assessments of the same emergency and areas. In cases where any damage assessment will do, the best available data are used until something more authoritative is available later in the event. Furthermore, certain organizations sometimes have their own missions, data collection needs, and internal review process and, in some cases, collect different data for the same event. For example, an agency might have a different rating system (e.g., adding a non-standardized "moderate" damage category, different from the FEMA schema). Or a data collection group might use the same survey technology, but the survey is configured for another information management system (e.g., the data and information gathered for a case management system). However, standardization of damage assessment data is crucial during a compilation process. Consistency in what datasets are drawn upon during an event ensures all partners are utilizing the same datasets for visualization and analysis purposes. When collecting damage assessment data, there should be consistency in the templating and how that data are created, reviewed, and approved for use by response and recovery partners. When a group's damage assessments are unique and idiosyncratic to their mission, or their data collection forms are focused on different data and information of the same event, or reports are coming it at different times, or partners don't know where data are located, then this can create information differences and communication hurdles that take more time to complete in the long run.

Excel spreadsheets embedded with macros are not really helping matters. As noted in the previous SIGDOC report, the files and infrastructure supporting them on the "Damage Assessment Forms, Templates \& Resources" page (e.g., "ia_pda_field_form.pdf” and "IDA_County_Summary_Form.xls") [2] were created at their time with the best intentions to support emergency workflows - and largely have for many years - but these same tools and services can sometimes also add unnecessarily to the workflow or inadvertently dictate it. Of course, local emergency managers do not solely rely on the files on Damage-Assessment.aspx; the disaster declaration and resultant aid do not hinge on these files alone during a disaster. Local emergency managers employ a variety of other systems for their own purposes. However, when they do use these forms, templates, and other resources for assessing and reporting individual, business, and local government damage, there are noted challenges confronting users, which include but are not limited to:

- Update resistance: Some files have not been modified since 2016, and these files are in older file formats (.doc and .xls instead of .docx and .xlsx), and some are somewhat inconsistently titled. Content in this format risks becoming siloed, out of date, or error prone (e.g., a call sign or other contact data could change and not be updated). Documentation updates are ultimately process heavy for individuals involved, 
in that updates are not automatic but instead require the added tasks associated with manually updating, which is based on a person's knowledge of the required update, as opposed to a machine change based on a permalink to an original source that automatically distributes the updated info to forms without needing a human to manually do it more than once or twice.

- Layout rigidity: The layout in forms is rigidly fixed, highly customized, hard to adjust, not easily adaptable to different screens, and not optimized for print-friendly sizes (e.g., letter/A4). Forms get spread across multiple pages in Excel, taking time and effort to adjust.

- Accessibility issues: Documentation does not follow current accessibility standards (color use, font size, alternative text, etc.).

- Collaborative lag: Documents are not tracked via a content management system that can keep an audit trail of what data users edit and update (like checking a document in/out of Microsoft SharePoint, using OneDrive, or using files on Google Drive). This leaves the job to the internally tracked changes and comments in Word documents and comments only in Excel files as the sole way to keep track of who edited/updated what when, where, and why. This can be relatively cumbersome to keep track of, given today's methods, not to mention content is hard to read and use when there are many comments, particularly in Excel files.

- Macro-laden files: Macros exist in the Excel forms (e.g., "IDA-Summary-Form.xls!Module3.CheckBox36_Click" and two other macros in the IDA Summary Form, an Excel spreadsheet used to compile damage assessment data). However, macros are often automatically disabled by security settings because of malware risks, and they trigger security warnings in office suites (e.g., LibreOffice, OpenOffice, Google Sheets, and Apple software). Employees who work for organizations often do not have the permission to use a macro on their work computer's Microsoft Office applications. This creates the need for help (e.g., asking a coworker, opening a help desk ticket with IT, and so on), which all adds time and steps to the process.

- Scripting workarounds: Given the age and legacy format of the damage assessment forms, templates, and resources, special scripts have been created to transfer data from localities' systems to the summary forms during the reporting phases of a declaration event (e.g., one local emergency management office has developed a Python script to export data into a format that can be opened, cut, and pasted into the IDA Summary Form).

While it is easy today to identify the pitfalls of using files from 2016 and technology dating back to the aughts (as ahead of its time as all this technology was then), it is much harder to solve the problems of transitioning the state to a more standardized system while meeting the needs of a diverse array of actors in the system (human and nonhuman). OEM is aware of this and has been researching and developing standardized location-based GIS damage assessments since 2016. The magnitude and scope of the catastrophic 2020 summer wildfire disaster event (a likely sign of summers to come) seemed to have put enough stress on the damage assessment process to expose areas of needed bolstering/improvement to the status-quo design of communication and, thus, played a role in a techno-methodological paradigm shift half a decade or more in the making.

\section{FUTURE-STATE SOLUTION: THE OREGON DAMAGE ASSESSMENT PROJECT}

As with any disaster for emergency management, reflecting on lessons learned is hardened into the process of planning for future events. With the devastation of the 2020 wildfires still in the public memory urging development of solutions in the aftermath of the problems that occurred, several new emergency management tools and services have been rolled out to the public in Oregon for the 2021 summer wildfire season and beyond, including the new statewide Oregon Alert (OR-Alert) program and notification system [5], the regional USGS ShakeAlert system along the Cascadia fault line [9], interactive maps at the city level [4] and county level [10], and other emergency systems.

Damage assessments also saw more attention after the wildfires based on lessons learned [8]. Working directly with each jurisdiction, agency, and partner involved with Oregon's response and recovery efforts, OEM launched a new initiative, the Oregon Damage Assessment Project (Figure 1) [11], which engages local, regional, tribal, state, federal, and private partners to develop a shared, standardized statewide survey template for gathering damage assessments moving forward. On the documentation level, this means a transition from $a$ to $b$ : $(a)$ macro-driven Excel spreadsheets as forms and templates, Word documents printed to PDF and manually uploaded to a server, and PowerPoint presentations as the main training material to $(b)$ a design of communication that uses all of the same content and genres, but different technologies that also expand the damage assessment genre by integrating it with shared location-based approaches, systems, and tools. The project takes advantage of Esri's ArcGIS Online (AGOL), as well as its Hub platform to provide a "one-stop shop" for damage assessments, including sharable 123Survey templates using common FEMA schema that can be customized, instructional manual and video guides, and other reference documentation (events, data, documents, apps, and maps). To view additional details, such as field surveys and review queues, emergency officials and other users can sign in to AGOL using the top right navigation option on the project's webpage.

\subsection{Project Background}

The origins of the Oregon Damage Assessment Project go back in many ways to 2016, when the state, multiple participating counties and jurisdictions, and other subject matter experts came together to test new GIS technology for damage assessments. After Oregon secured a statewide ArcGIS Online (AGOL) license with Esri, this provided the potential for every jurisdiction in Oregon to get an AGOL account and thus access new damage assessment tools. To get an AGOL account prior to starting a damage assessment, jurisdictions coordinate with the OEM GIS coordinator (also supported by the State of Oregon GIS team) or their own internal AGOL administrator to have accounts issued to individuals for access to the data during the events. Counties and partners are assigned 


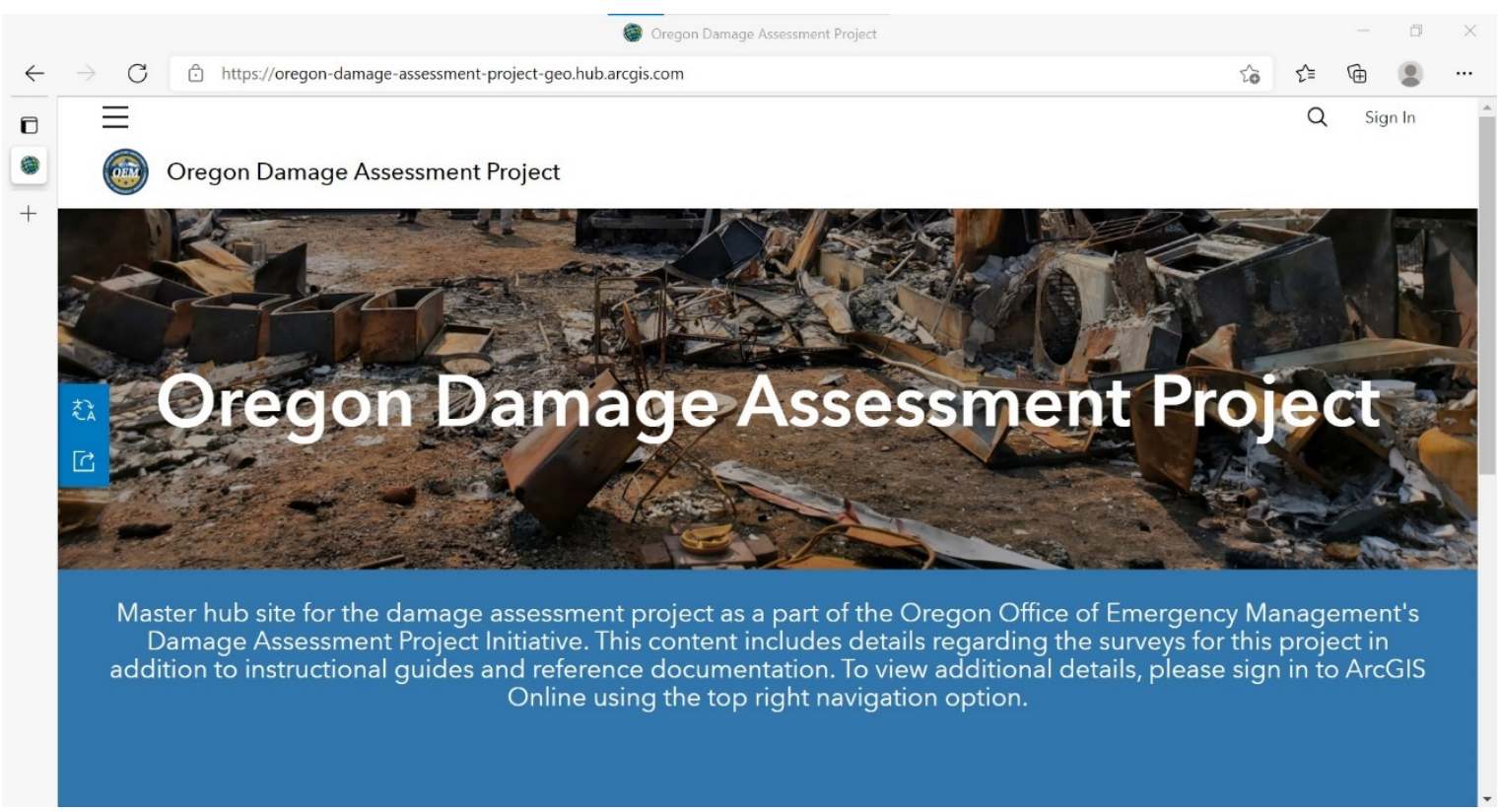

Figure 1: Oregon Damage Assessment Project Geo Hub Home Page

"community accounts" in Geo Hub where data and information for damage assessments are collected using Survey123 forms and "QuickCapture" forms stored within the Oregon AGOL organization. The cloud-hosted platform allows for sharing among multiple partners in secured groups. Damage assessment data can be stored as a hosted feature service to allow for additional views of damage metrics and other measures, including visualizations within dashboards and other application templates [12].

In many disaster-and-recovery events, public assistance (PA) forms, templates, and resources for affected local governments are part of the declaration process, but PA has not been part of the current scope of the Oregon Damage Assessment Project, only home and business damage assessments for individual assistance (IA) are currently in scope. The IA program is also sometimes called "human services" assistance because IA assists individuals and families, as well as businesses and private non-profit organizations (underneath the U.S. Small Business Administration). With IA, damage assessments are high volume (number of individuals affected), but their surveys are relatively easy to implement because data and information rely on location-specific points (i.e., homes and businesses) PA for local government agencies, on the other hand, is lower volume than IA but more complicated because PA calculations not only include stationary items (e.g., utility lines and infrastructure) but also other more complicated data points, such as "protective measures" (e.g., the police force in a locality might request public assistance for providing protective measures). However, the Oregon Damage Assessment Project with IA does give some insight into where the PA could possibly be headed in the future. In the process of IA being tested and rolled out for the 2021 summer, for example, this next-generation solution implementation for IA could give rise to adoption by public agencies in local governments.
To learn more about the project, anyone can visit and explore the Oregon Damage Assessment Project Geo Hub website themselves, as well review the "Damage Assessment Project Reference Guide," which provides new users steps for gathering damage assessment data for a disaster declared in the emergency manager's jurisdiction (city, county, other), relevant information regarding setup of teams, information typically gathered during these events, steps for conducting damage assessments, and accessing the data once gathered [12]. Even the reference guide signals a change in the shifting software approach; instead of a MS Word file, the manual for the solution is a Google Doc with permission settings that allow for online viewers and can be viewed in most browsers, on most devices, and exported to different file formats.

\subsection{User Types, Tools \& Dashboards}

In addition to the public-facing side of the Oregon Damage Assessment Project Geo Hub website, there are two types of user groups who can $\log$ in with their AGOL account credentials to get much deeper access to data and damage assessment features on AGOL platform:

- Field data workers see the "Forms and Training" tab/view.

- For those who get review status, they are provided a view of the "Government Partners" or "Counties" tab.

With the dashboard approach, users can access an individualized digital interface and functions that integrate with data systems, provide streamline workflows, and allow for more easily verified data for decision making.

4.2.1 Data Collector Forms \& Training Dashboard. Local users collecting field data have access to the "Forms and Training" tab, which contains the essential components provided to field data collectors. The survey forms are easy to share. Hyperlinks to the templates 
are provided along with $\mathrm{QR}$ codes, which can be scanned from one device using another device's camera. Embed code is also provided for embedding links in other platforms. This includes links to all the different types of damage assessment surveys: quick-capture assessments (aka, "rapid" or "windshield"), damage assessments for homes and businesses, as well as public damage assessments. Also provided is reference documentation, not only a project guide/manual but a set of videos on how to get set up as well. Below are more details on the "QuickCapture" and "IDA" survey forms.

Rapid "QuickCapture" Assessment Form: The "quick capture" survey form takes care of the rapid assessments (aka, "windshield surveys") that are common to any emergency, where teams determine the basic information about property damages in affected areas (Figure 2) [12]. In addition to local emergency management staff, the user-end team for a rapid assessment can include American Red Cross, volunteer organizations such as a community emergency response team (CERT), faith-based organizations, search and rescue, and local fire departments. Preliminary data are a short list of must-have items, including the damage category, location, and photos of the damage. [12].

Initial Damage Assessment (IDA) Form: During the initial damage assessment (IDA) phase, follow-on surveys are conducted with homeowners, business owners, and building officials. This component of damage assessment can be done in person or remotely based upon local capability. The end-user team for this step changes composition from the rapid assessment as well and can include building inspectors and/or assessors, community development representatives, local emergency management staff, local business partnerships (e.g., main-street organizations and others to assist with business impact data gathering efforts or local floodplain manager and designees). Jurisdictions can also utilize call centers for damage assessment reporting remotely or data entry through publicly submitted online forms. Because of the nature of this step, data gathering includes additional details about the property (quality of construction, foundation type, etc.). If homeowners or renters are available, additional questions are asked (e.g., are you an owner or renter; do you have a tribal affiliation; what is your primary residence; do you have insurance?). Sometimes, substantial damage assessments in floodplains require a floodplain manager or their designee to conduct the damage assessment. There are also applied technology county (ATC) assessments, which require trained building officials to conduct post-earthquake or wind/flood assessments of structures, also known as, "tagging" (building name, number of stories, if building is used in an emergency, placard rating, etc.). Photos are also a requirement in this step, and field reporters collect photos of the site, site address, context images, curbside images, and close-up images. Figure 3 shows the Survey123 interface of the IA individual assistance damage assessment form. See the project reference guide for more details, as well as an image of the business assistance form, which looks similar to the IA form, but gathers data for businesses (estimated losses for inventory and contents, projected losses next quarter, etc.) [12].

During the IDA, a jurisdiction may also choose to utilize an online form for the general public to submit their own damages for both the home impacts and business impacts. The data gathered via this methodology is the same as if sending individuals into the field, but this may require additional validation prior to incorporation

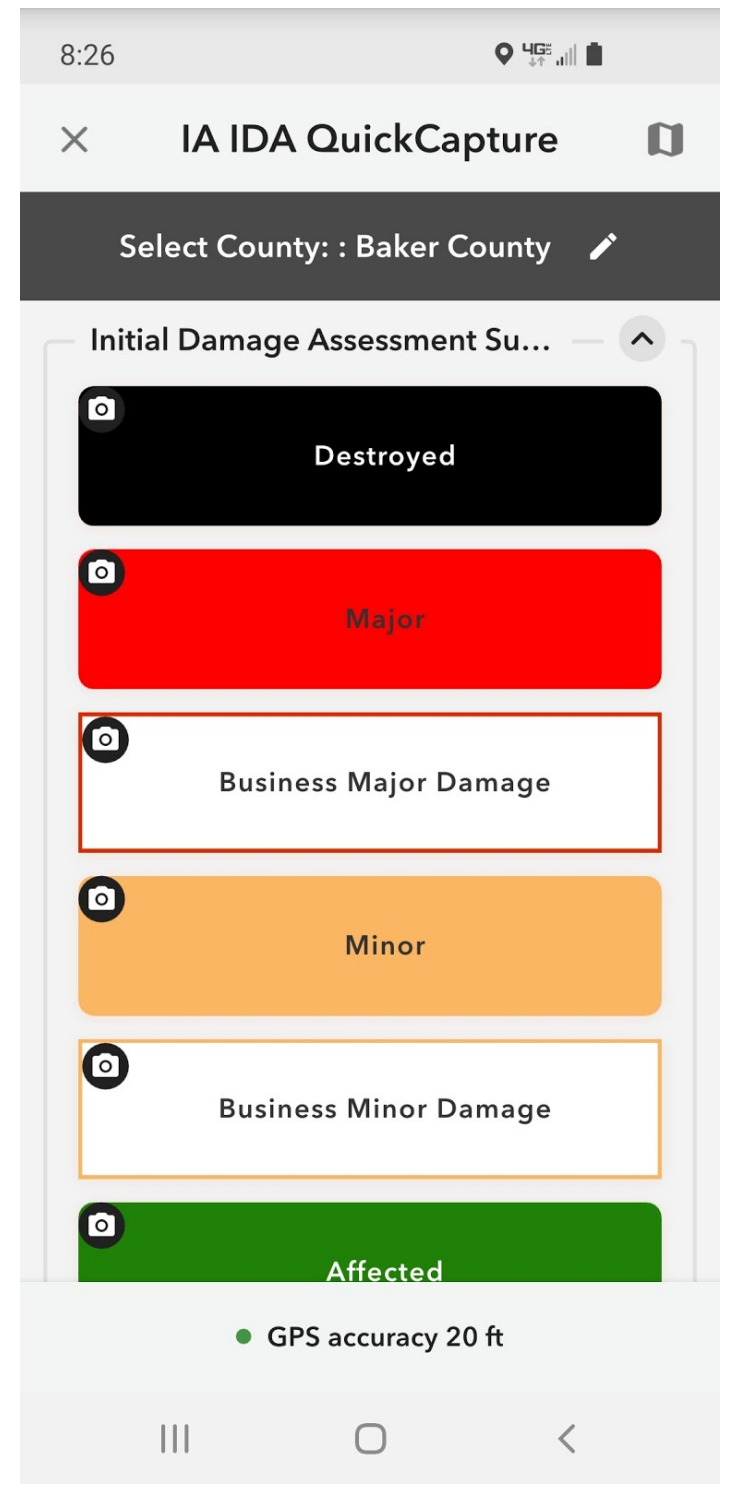

Figure 2: Individual Assistance QuickCapture Form

into the official submittal for certain jurisdictions. Figure 4 shows a Survey123 interface for the "Public Home Damages Collection Survey," but there is also a similarly designed "Business Damage Assessment Collection Survey" with different business-related questions related to standard requirements [12].

Compared to the Excel spreadsheets and PDFs of DamageAssessment.aspx, the user experience changes dramatically with these relatively newer types of surveys, including:

- Hardware and software agnostic: Surveys function on desktops, laptops, smart devices like tablets, phones, other mobile devices. They work in browsers or as a native application on a device, and they allow for capturing data in environments disconnected from the internet. 


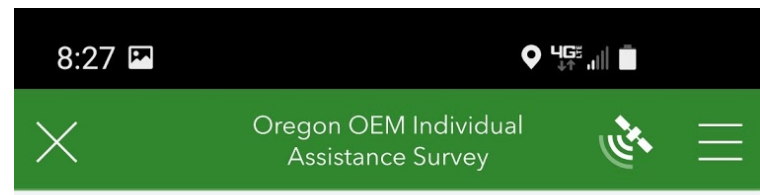

\section{OEM Individual} - Assistance Collection Survey

\section{Location of the damage: *}

This will auto-fill based upon your location. If no location is showing, please select from map or use address search to locate the property.

\section{$44^{\circ} 56^{\prime} \mathrm{N} 122^{\circ} 60^{\prime} \mathrm{W}$}

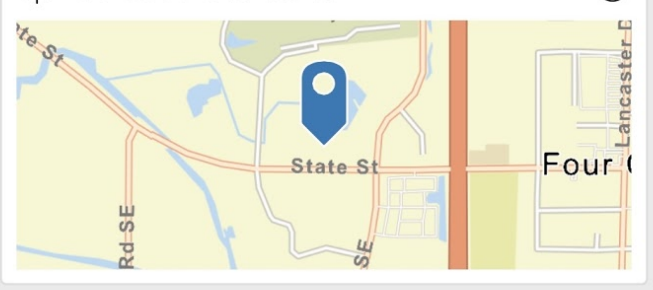

$\checkmark$ Location Information:

Street Address:

*Confirm address - New divisions may not reflect accurate location.

3225 State St

(X)

Unit or Manufacture Home Space

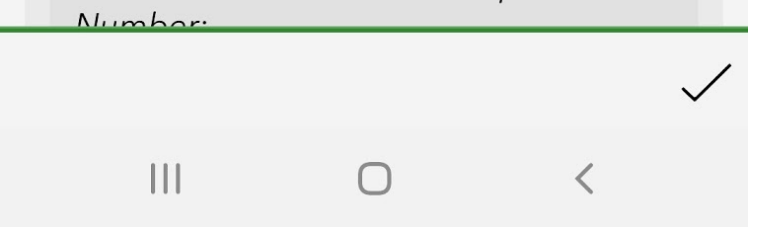

Figure 3: Individual Assistance Collection Survey

- Functional and fluid: The name Survey123 outlines the basic concept: a form-centric data-gathering survey in three development phases: (1) create, (2) share, and (3) analyze surveys. Forms are easier to fill out and edit than Excel spreadsheets; they have predefined questions that use skip logic, predefined answers, embedded audio and images, camera integration, data visualizations, and offer text in multiple languages. Surveys work for multiple genres of damage assessments, from local rapid collection forms to FEMA surveys.

- Collaboratively inclined: Digital data collection is designed around easy adoption and adaptation to multiple settings for teams in different locations during emergency operations in rapidly escalating scenarios. Users can analyze results quickly in changing field events and upload data securely for further analysis. Data and workflows are a connected continuum using tools and available services from the state to save time, energy, and duplicative/redundant efforts - when it is needed the most during an emergency and in recovery.

- Cloud-hosted: Data captured in Survey123 is available in real-time on the ArcGIS server stack platform. Hosting that can handle emergency capacities of users using the platform is important because high usage can bog down regular website servers and threaten to inhibit services [8].

- Standardized and templated: Instead of a MS Excel file, the form design template is an online Google Sheet with permission settings ArcGIS Survey123 supports the XLSForm specification and has a streamlined UX with skip logic, pre-filled/easy-fill answers, defaults, and support for multiple languages, all within the FEMA schema. See Figure 5 for a screen shot of the "Form Design Template" file [13]. Parent template forms keep all users standardized and following FEMA standards, but there is also easy configurability for local requirements (e.g., adding special flood plain datagathering requirements for flood plain managers and the Oregon Department of Land Conservation and Development to collect data in conjunction with the county damage assessment process for FEMA). This is instead of the county configuring themselves to the template (e.g., special Python scripts that export data specifically for cutting and pasting into the IDA summary .xls file).

4.2.2 Data Reviewer Dashboards (County, Tribal \& State Partners). States coordinate damage assessments differently. Some take more state-run damage assessments, but there are some (e.g., Oregon) that have an emergency manager or coordinator in each county, who then works with other partner counties and localities like cities and other jurisdictions. Some counties, such as those with large cities and densely populated metropolitan areas, have managers of a small staff, including one or more assigned GIS specialists, operation specialists, technical leads, and other subject matter experts devoted to emergency management coordination. Some counties only have close corollaries, such as the sheriff or other emergency management services like 911 . Some have experience with GIS and others do not. Thus, the role, experience, and number of reviewers varies from jurisdiction to jurisdiction.

Users in Oregon who are added into the damage assessment reviewers group have access to a page for their specific jurisdiction after signing in to the main Geo Hub site (Figure 6) [12]. Data reviewers use their assigned AGOL credentials to sign in on the top right of the screen, click on their jurisdiction page on the top menu navigation bar to view their result, and check visualizations based upon the data collected. Views of the data created for review are based upon the jurisdiction field of the data (i.e., only a Baker County accounts see Baker County's data). From here, data reviewers are able to edit records submitted from the field data collectors (in addition to submitted records from the public) and then approve or reject the results of data collected in the field and via public 


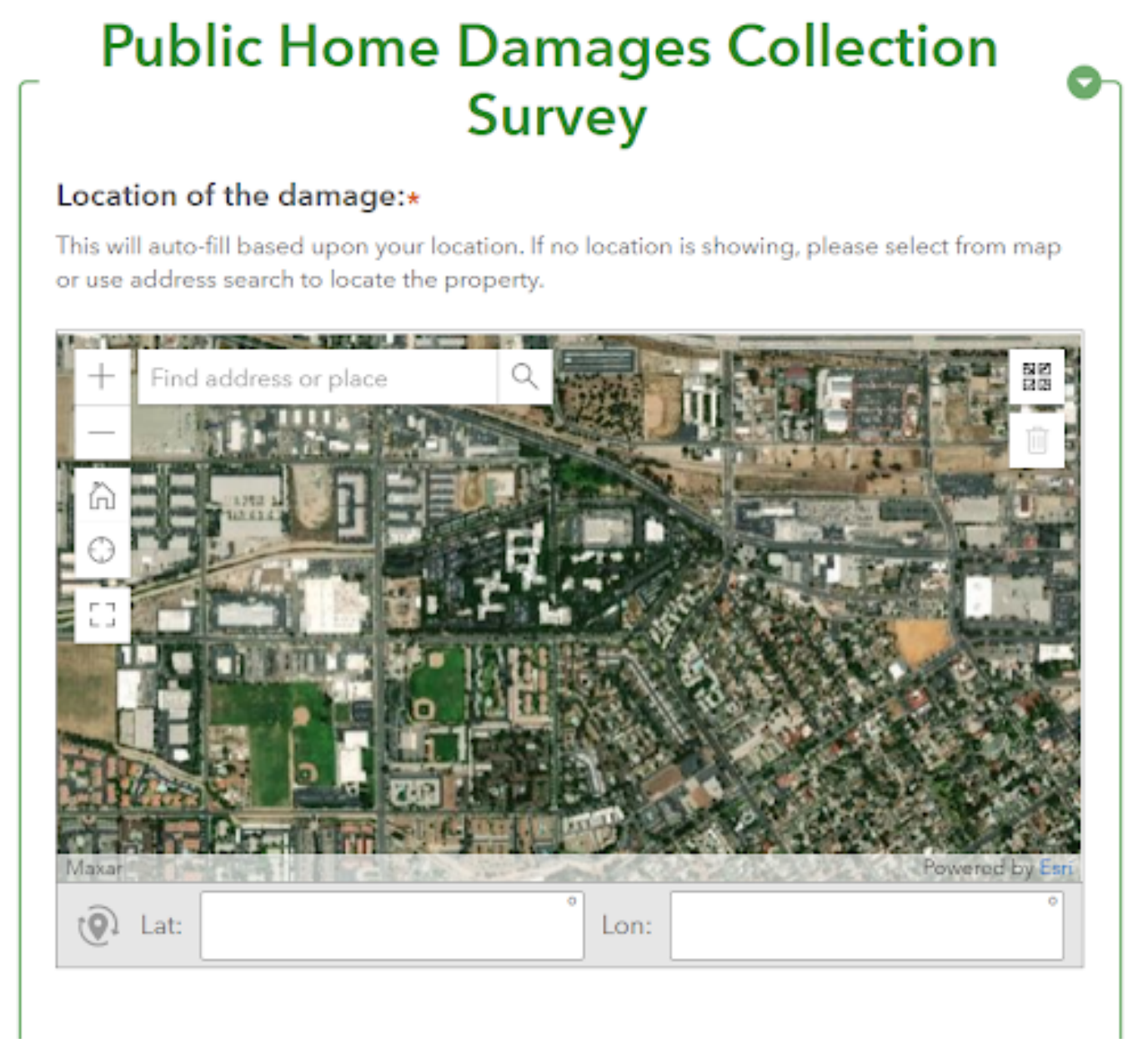

Figure 4: Public Home Damages Collection Survey

forms. Viewable damage assessment data include business impacts with edit capability for quality checking (QC) and quality assurance (QA), individual assistance requests with edit capability for $\mathrm{QC} / \mathrm{QA}$, as well as American Red Cross assessments and Oregon State Fire Marshal assessments (the last two for reference). Reviewers can also view damage assessment attachments the images that were captured as a part of the damage assessment data collection, and images auto-update based upon the latest data gathered [12].

A simplified set of dashboards have been created to allow for editing either the home or business review dashboard (Figure 7) [12]. Each dashboard allows users (e.g., local emergency management official in Baker County) to review the records submitted for home or business impacts and update the information using a dashboard view of the Survey123 form for that particular record. Users can view all damage assessments collected for impacts using the map and the list on the left side of the screen. Records within this view are updated every five minutes. More recent damage assessments will be displayed as they are collected. Records are sorted by the $\mathrm{QA} / \mathrm{QC}$ status (items needing attention/review first), then by property address. The record of interest is the leftmost pane. Records with a red background indicate that they require review (QA/QC completed equals "No"). Once the record is selected, data and information displays in the closet left-of-center pane on the dashboard. Within this panel, reviewers update any necessary items, and then switch the "QA/QC Reviewed" option to "Yes" to indicate that the record has been reviewed and approved. Clicking the "Submit" button on the bottom of the form completes the editing for that record. These steps are repeated for any other records requiring review. A "How To Use This Dashboard" section on the rightmost pane walks users through the steps of editing records via the dashboard [12]. The process is made easier for users by programming many of the repetitive and redundant tasks that would normally have to be manually done. 


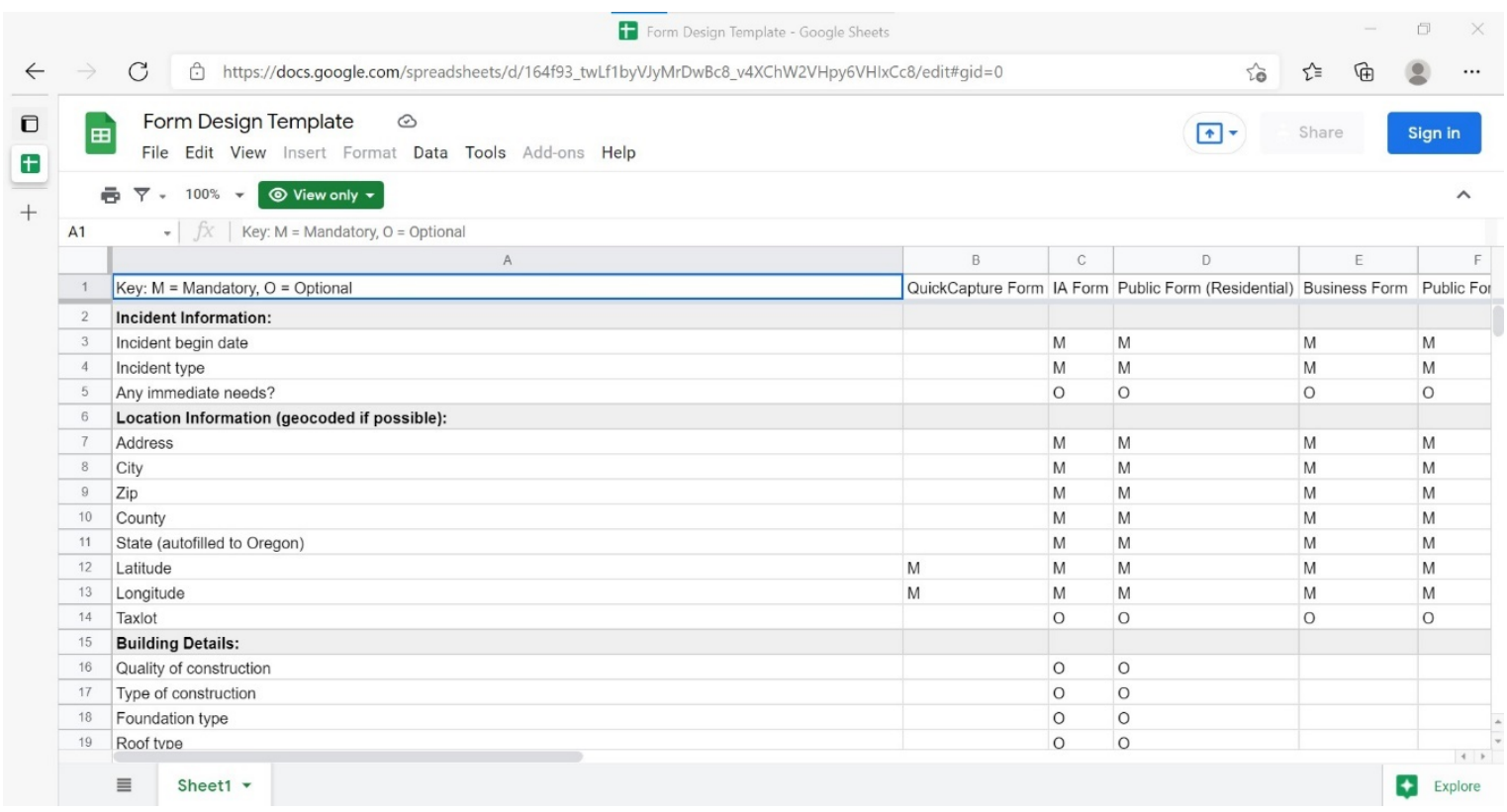

Figure 5: Form Design Template Google Sheet

\section{Baker County}

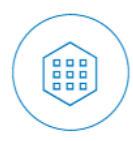

Baker County Business Survey Template Reports

This file contains information regarding the damage assessments for business impacts.

\section{View Details}

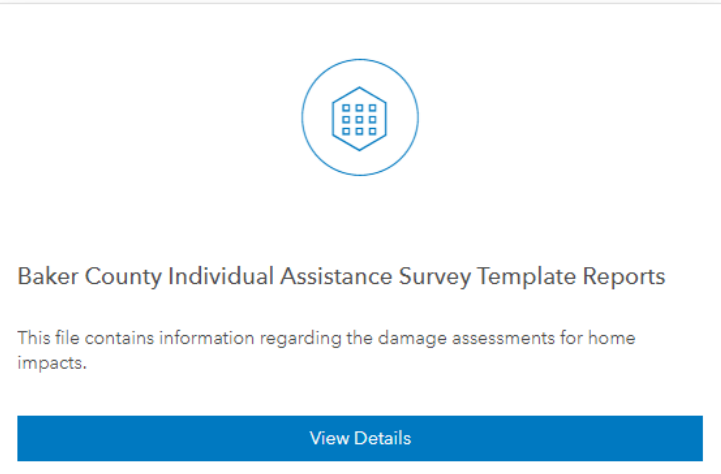

Baker County Damage Assessments Attachment Viewer i

\& Baker County Individual Assist... .

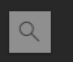

Welcome!

View a Incation's attachmento

Figure 6: County or Tribal Jurisdiction Dashboard 


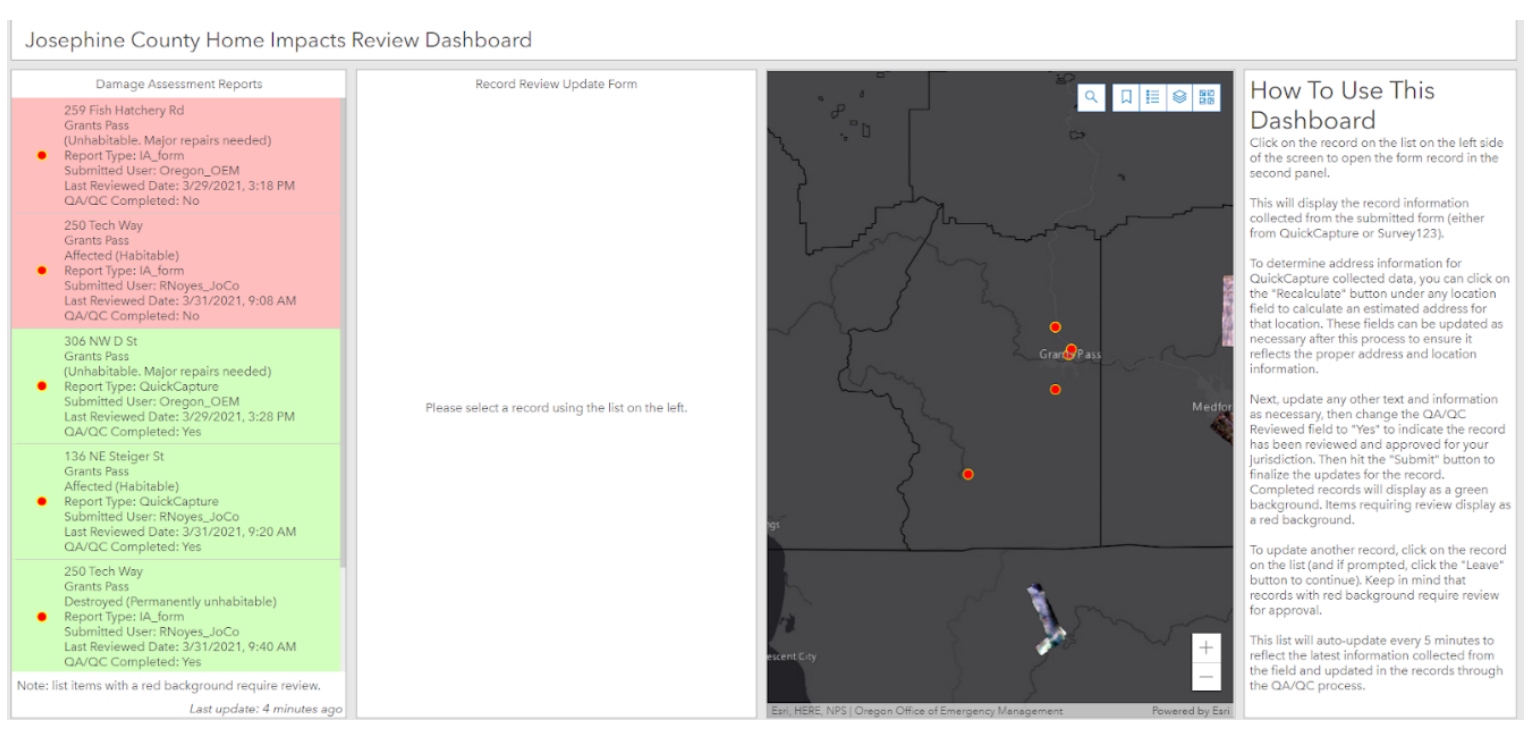

Figure 7: County Home Impacts Review Dashboard

\section{State Partner Awareness}

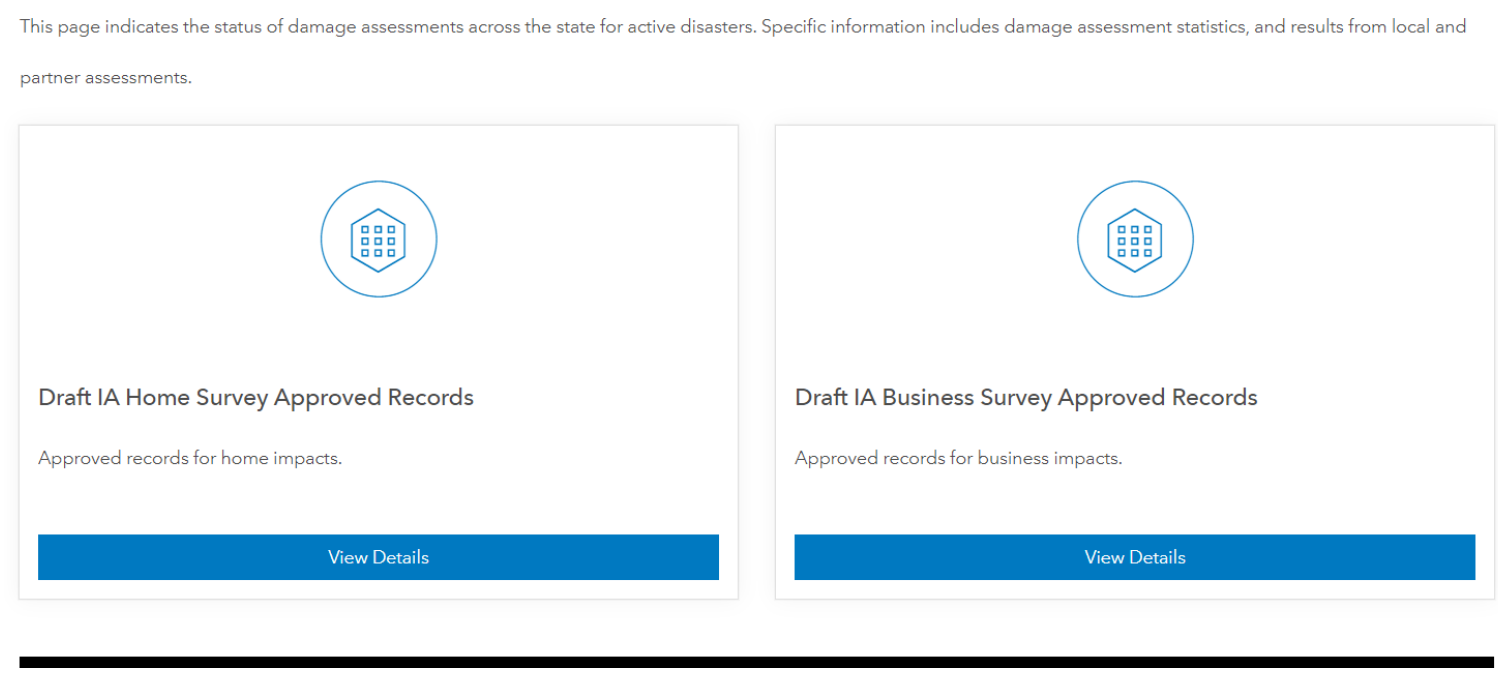

Figure 8: State Partner Dashboard

There is also a "State Partners" awareness page that lists home and business survey records approved by the local/tribal jurisdiction representing the home impacts damage assessments (Figure 8) [12].

The views of these data can be brought into additional mapping applications (e.g., ArcMap and ArcGIS Pro). These views can be downloaded as backup copies for internal purposes by clicking on the "Download" button for the specific data layer (Figure 9) [12].
Data can also be visualized within a web map on the overview page for that data layer. The "Total Assessments Dashboard" indicates the status of assessments in jurisdictions and reflects the number of assessments currently conducted, as well as how many have been approved by jurisdiction for both homes and business assessments (Figure 10) [12].

The "Damages at a Glance Dashboard" indicates the current at-a-glance statistics based off the approved records from local jurisdictions and reflects the number of major and minor damaged 


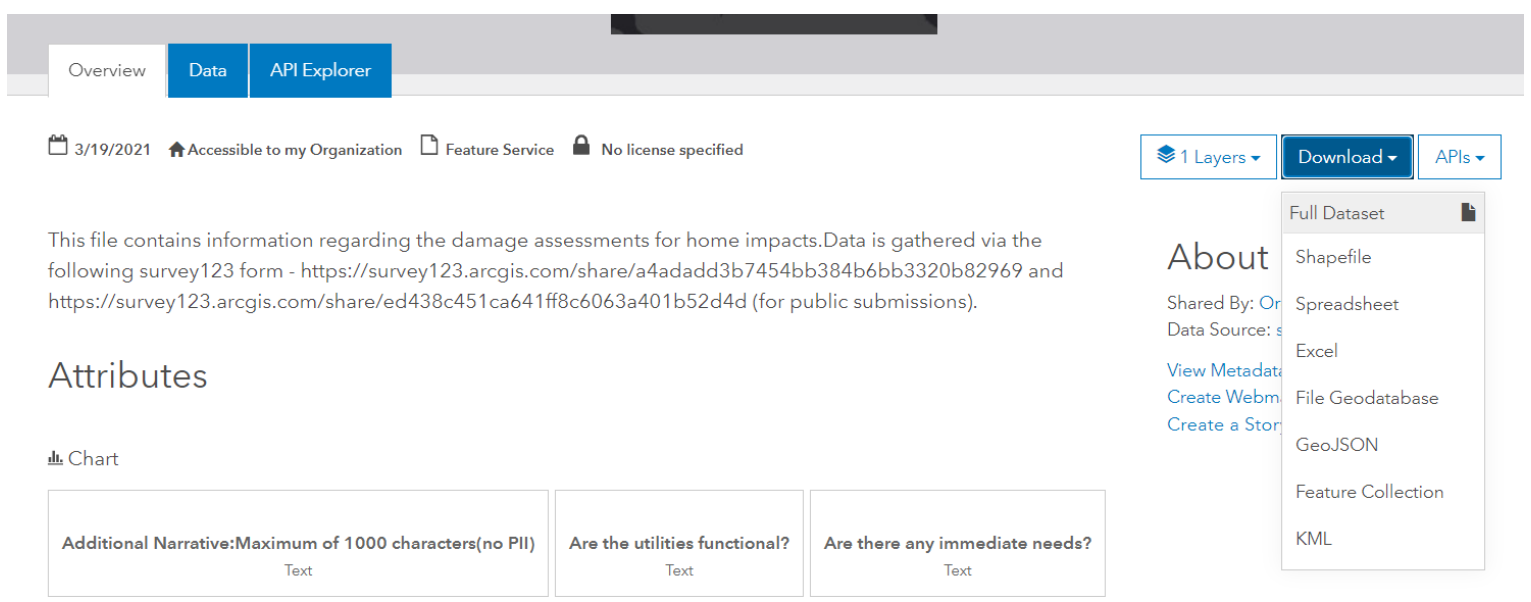

Figure 9: Damage Assessment Data Downloads \& API Explorer

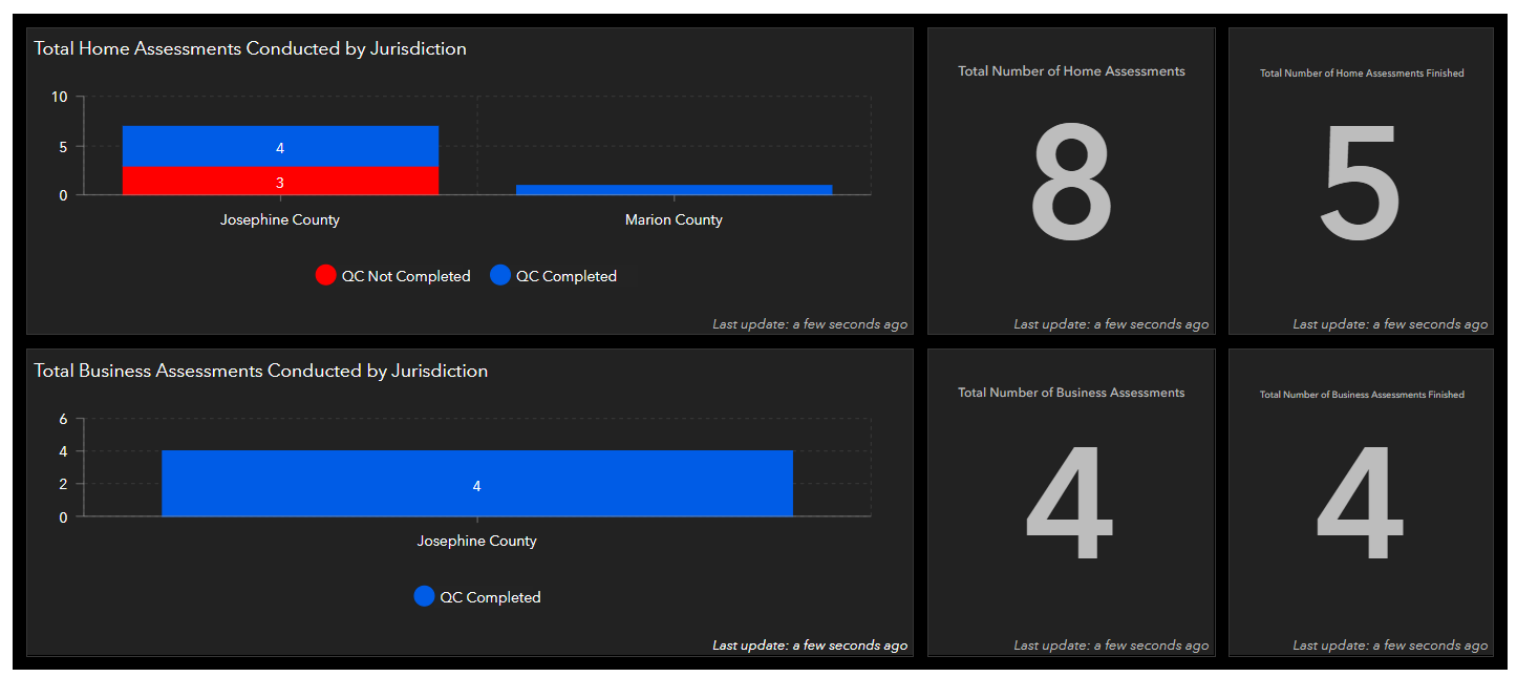

Figure 10: Total Assessments Dashboard

businesses and the number of destroyed and major damaged homes, both in addition to breakdowns by jurisdiction (Figure 11) [12].

\section{DISCUSSION: TECHNOLOGICAL TRANSITION \& USER BUY-IN}

Oregon's statewide damage assessment software solution continues to evolve, as more experience is gained by those implementing and using the most recently added GIS tools and services. Fueled by the worst wildfire season on record in Oregon, the plan was to get the project rolling before another fire season started. Although 2020 wildfire recovery, COVID-19 vaccinations, mudslides, and ice storms took precedent and slowed implementation, the project Geo Hub site and templates were published and put into rotation for the spring 2021, which saw an early and intense wildfire season that included a spate of days under a heat dome that reached historically high temperatures, as well as the Bootleg Fire and other wildfires throughout the state.
In addition to the Oregon Damage Assessment Project, there are other signs that the public will see more location-based methodologies tied into emergency management communication in Oregon. OEM's main Geo Hub website, for example, features spatial data visualizations, videos, mapping applications, and other functionality to "paint a more detailed picture" and provide more facts-based storytelling for what is happening in people's areas before, during, and after a disaster or other emergency event [14]. The Geo Hub site visualizes an assortment of incident data and information, including a hazards overview, COVID-19 cases, weather, latest earthquakes, fire activity, drought status, volcano activity, transportation network status/impacts, shelter activity, emergency operations center activity, and FEMA daily operations briefings. Visitors can access data from damage assessments, read stories, explore recent disasters, watch mapping-related videos, view social media, and access public data (Figure 12).

The Geo Hub platform, statewide Esri license, and overall GIS approach in Oregon are perhaps evidence of a type of broader change 


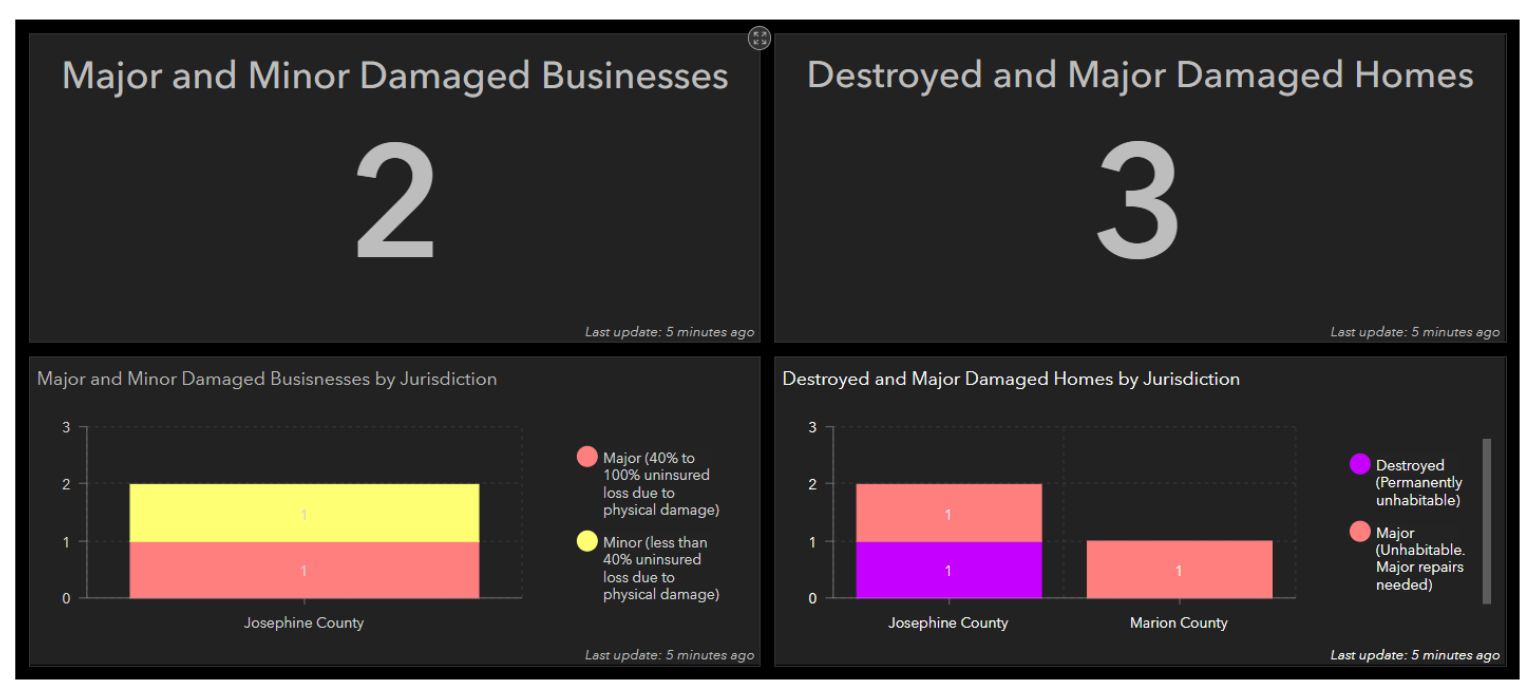

Figure 11: Damage-at-a-Glance Dashboard

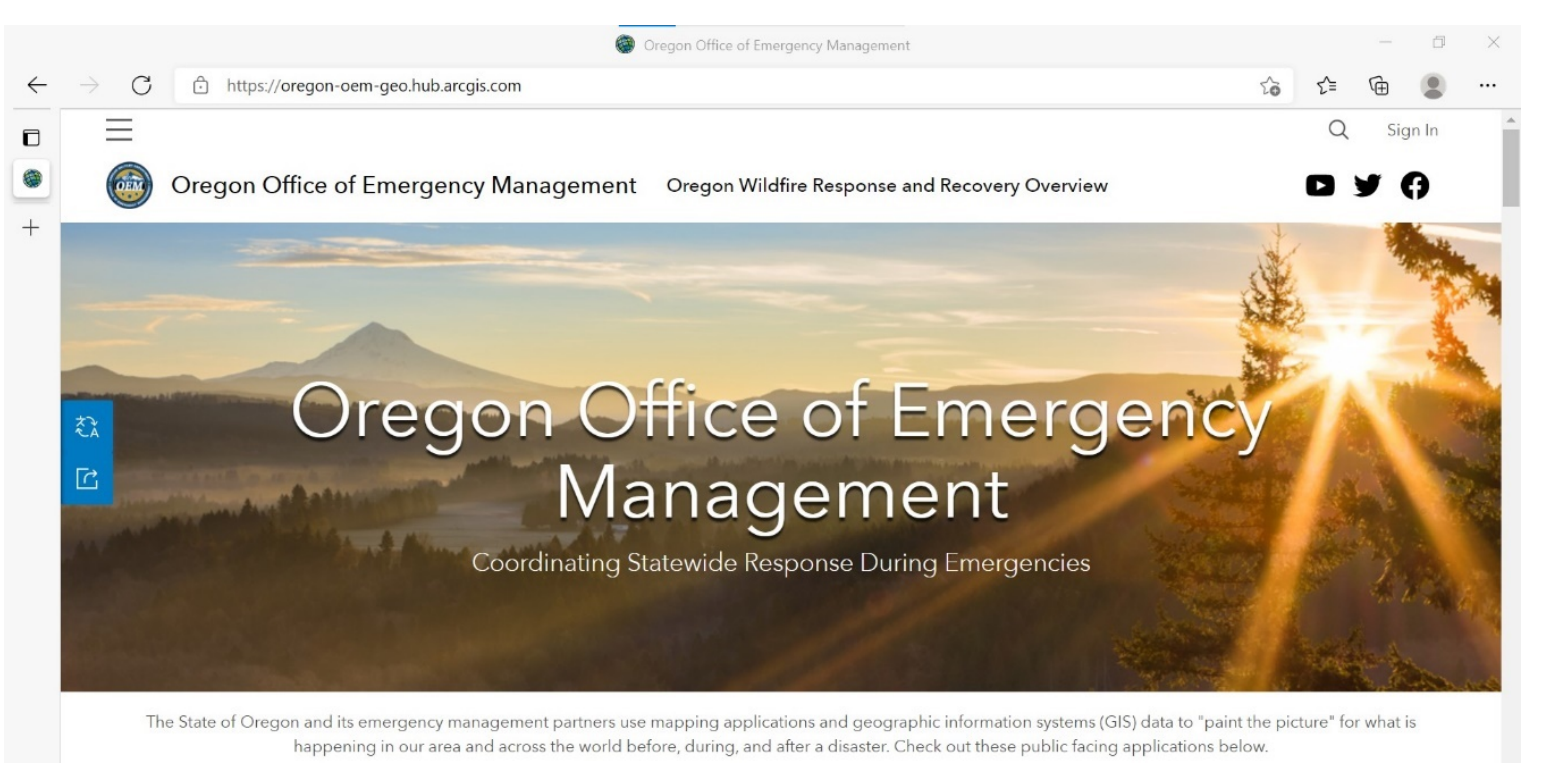

Figure 12: OEM Public-Facing Geo Hub ArcGIS Site

in the way that governments and other organizations are starting to approach emergency events. GIS technologies such as framework spatial data infrastructures (SDI), ArcGIS Online (AGOL), Survey123, XLSForm, etc. - all of these technologies are attractive because, put together into the user experience, they visualize tabular data for people and allow multiple users of various permission levels to make simple updates that propagate through multiple views across the platform. This lightens the relative load by reducing paperwork, redundancy, repetitive tasks, opportunities for error, etc. Different users and user groups can also build off these existing tools, instead of custom building their own and having issues with it working for others and/or those who come after them.
This approach also makes it easier to train, because the spatial technology is a known quantity that other groups use, not a custom build that perhaps might need more specialized training for people.

Building a new set of tools and services for users is one thing, but user buy-in and adoption is another, especially to non-GIS users and those with previously established processes that require effort to change. Adoption hinges on an assortment of known and unknown individual feelings and behaviors, as well as group policies, not to mention access to technology. Web maps, for example, can be hard to use when users must figure out what to point at and click to enter or edit data and text. Lavish features that are actually laborious or do not work turn users off as well, or the old ways of cutting and 
pasting might seem outdated, but a new way represents too much change. Availability is also not necessarily accessibility.

Motivations to adopt come from many vectors. Some are personal. Some people for instance need to see that new technology is a good idea because it saves them time and energy when they need it the most. In this way, added productivity, ease of use, and familiarity with the UX of other applications in users' lives can help adoption rates. Technology that appeals to a smooth user experience has become part of the expectation from computing machinery and the design of communication. Overall, it would appear this trend has caught up to damage assessments. For example, XLSForm is a tabulated spreadsheet that is easily editable. Survey123, as the name suggestions, has interfaces and interaction design that appeal to the type of usability that focuses itself within three clicks to the content that a user needs. Field data collection and reviewer data are shown in familiar formats that people are used to seeing in common form-based and polling software (e.g., Doodle, Facebook, Zoom, TurboTax, and other similarly designed interfaces). Esri's Hub website provides cloud-based hosting and individualized dashboard views.

Of course, there are more than just personal usability motivations that drive adoption; it is also important sometimes for users to be introduced to new technological tools and services through opinion leaders. This represents not just individuals affecting the adoption of other individuals, but also a jurisdiction affecting other jurisdictions. For example, one leading stakeholder county might sign on to a project, and this leads to other counties signing on to become stakeholders. The goal is to eventually obtain a critical mass that is significant enough to argue for the system's existence. Otherwise, software risks not being used at all, a tool or service that exists but is not widely used.

For the OEM Damage Assessment Project, the approach to introducing new damage assessments to both individuals and groups has been to think globally about technological trends and initiatives but at the same time give emergency personnel at localities services and tools that are easy to use and modulate for their own purposes but that also tie into the whole. This tools-and-service approach gives software to the groups who need it and allows them agency over what they do with it, but it is already standardized with state and FEMA requirements. Equipped with these basic tools and services, groups are then able to see over time what is capable and start envisioning modifications and changes (e.g., using the estimated population data and housing data in future damage assessments). Perhaps localities might eventually start working with Oregon's framework implementation team in the state to start proactively identifying authoritative data sets for the state of Oregon framework reference data and create prepackaged, future-looking spatial data sets that are configured based on the type of emergency event.

In the end, the damage assessment methodology in Oregon has largely remained the same as that which was profiled in the last report, where federal and state authorities work in concert with local jurisdictions. Now, however, jurisdictions are provided with statewide licensing, standardized templates, sharable documents, and multimodal audio-visual training. In this way, the hope is that a group of close to 150 local emergency managers spread throughout different jurisdictions (field data collectors and/or field data reviewers) and a devoted network of state and federal officials can more easily handle and coordinate damage assessments as they apply to various areas and disaster events (damage assessments being just one task among many during a disaster declaration) - at least damage assessments for homes and businesses for now; perhaps public agencies will also adopt similar methodologies in the future.

\section{CONCLUSION: THE FUTURE OF DISASTER DOCUMENTATION}

Without the constant presence of disaster, the longer an emergency event recedes into the past, the more the exigency fades in the public memory, and the harder it seems to be able to convince people within and outside a locality or region (taxpayers, policy makers, decision makers, and others) that resources should be allocated to plan for and mitigate future ones (investment in more planning and staffing, as well as upgraded hardware and software, and so on). Emergency managers in Oregon are often a singular staff position in their jurisdiction's organizational chart. In this way, many are an "army of one," as one emergency management official framed the role. Some local emergency managers seem to also often be in a "constant battle" of "selling" emergency management to both administrators and the public, as another emergency manager put it. Perhaps this is all changing, however.

In the last 2019 report, pre-pandemic, the collective mind of the public in the Pacific Northwest had been captured by reporting on the any-day-now presence of the Cascadia fault line and earthquake zone, the "Big One" [15]. In 2020, it turns out that the next disaster lurking was not an earthquake but the chronic-onset disaster of the virus SARS-CoV-2 and the COVID-19 respiratory disease. Then the existential threat of climate change reared back into view in Oregon with the historic wildfires of 2020, which cut through the state and left deep scars. Some lost their lives. Many lost homes and livelihoods. Towns and regions throughout the state were left in ashes, and few were spared the heavy blanket of smoke that covered many areas for more than a week in some places.

The abatement of extreme climate events seems unlikely. Research has shown that the warming climate is making heat waves, droughts, floods, tornadoes, etc., more frequent and intense, leaving a broader trail of damage to assess. The extremes have been alarming even for scientists who study climate phenomena. In addition to one the earliest wildfire seasons in 2021 [16], the Pacific Northwest spent several days of high summer under an oppressive heat dome that reached 116 degrees in Portland and killed hundreds of people in the area and an estimated billion or more sea creatures [17]. The Bootleg Fire in southern Oregon scorched hundreds of thousands of square miles to become the biggest fire in the United States, the warming climate making extreme events like this more frequent and intense [18]. These are just a few examples from the Pacific Northwest. Approximately 95 percent of western states face drought and dry conditions. According to the National Oceanic and Atmospheric Administration, June 2021 was the hottest one recorded in the United States since record keeping began, and the year to date was among the planet's top-ten warmest, with arctic sea ice coverage the sixth smallest on record. According to the latest report from the Intergovernmental Panel on Climate Change, scientists are observing changes in the planet's climate in every region and across the whole climate system, and many of the changes 
observed in the climate are unprecedented in thousands, if not hundreds of thousands of years, and some of the changes already set in motion, such as continued sea level rise, are irreversible over hundreds to thousands of years [19].

With a new generation of climate disaster impact comes a new generation of damage to assess. One 2021 retrospective study [20] demonstrated how human-caused climate change caused an additional $\$ 8.1 \mathrm{~B}$ of $\$ 62 \mathrm{~B}$ in damages when Hurricane Sandy swept up the eastern coastline in 2012, flooding subways and neighborhoods from Florida to Maine, including major damage in the New York area, which has seen sea level rise approximately eight inches at the tip of Manhattan since 1950. Researchers in this study found that human-induced sea level rise during Sandy played a significant role, affecting an additional 71,000 people and flooding 36,000 more homes. The article argues for more research on the current costs of a warming world, and not only could old damage assessment report data shed light on the rate and impact of historic changes in many other regions, but new damage assessment technologies could help play a role in future reporting.

With the uptick in disasters (e.g., climate change, epidemics) come more wicked problems and the need for next-generation tools to address the added level of impact and overall damage. When the frequency and magnitude of events increase, so do the number of reporting entities, facts, figures, and files to manage. This increased quantity of data and information, especially if non-standardized, increases the risk of a legacy documentation system and process bottlenecking the data and workflow through the event and into its aftermath, which is a prospect that was made more evident in light of the 2020 wildfire season in Oregon.

Damage assessments are also just one type of disaster documentation, and other process areas of the assessment-to-assistance spectrum have their noted problems. The individual assistance application process, for instance, can be fraught. In the wake of the catastrophic wildfires of 2020 , for example, more than 24,000 Oregonians applied for federal disaster assistance, but roughly 57 percent of them were denied with only 40 appeals approved) [21]. While mistakes, misunderstandings, and outright fraud are not uncommon, some people were reportedly denied because of clerical errors, missing documentation, mismatched information with FEMA databases and their third-party contractor databases, multiple households living on a property, other unconventional living conditions, having a foreign name that is sometimes Anglicized or misspelled, having two last names that are sometimes hyphenated, and misunderstanding how to amend applications with other needed documentation [21]. These are not new issues, but with a growing level of applications, perhaps there is more call to explore possible solutions and see what technical professionals and professional communication designers can do to help (e.g., inform and enable applicants to engage in the process by designing for their needs, including those with the greatest needs, such as creating new multilingual applications and translation services, eliminating simple linguistic mishaps, fixing noted documentation problems like designing self-certifying homeownership documentation in lieu of title documents, migrating information from damage assessments into application processes, and so on).

Whatever or however it happens, the status quo seems to be changing regardless, as the pandemic, climate change, etc., have altered the nature of the problems. While hurricanes roil the gulf and eastern coastline, high rains flood inland areas, and wildfires rage in the west, what seems to be getting easier is pitching and selling the public on support for the next-generation emergency management information systems and disaster documentation (new damage assessment software, assistance-application technologies, and so on) - as a new generation of disasters fueled by humancaused climate change becomes more emergent and frequent, and more and more people are affected, less is left to the imagination.

After the 2020 wildfire damage in Oregon, one of the worst on record, it was easy to see in hindsight that standardization would have helped the data sift. Perhaps if the data processing were mitigated, this could help emergency managers and others involved in future disaster events devote more energy to mitigating fallout from the emergency and helping people, instead of copying and pasting text or rehashing damage assessment data. New enterprise data management systems being implemented need to be watched carefully, as well as cyber-secured, but if implemented and adopted, they might allow for this sometimes extreme user experience to be streamlined and the data and information in upstream workflows to be automatically archived and connected to lateral and downstream workflows, as the nonhuman computing element gains more agency as a Latourian actor in the event, helping to better inform human decision makers and those in affected communities [22].

This damage assessment evolution also seems to be a part of an overall data-sharing paradigm shift and move toward shared GIS and spatial data infrastructures, perhaps even one at the national or international level. Equitable access to common, authoritative, secure spatial data and tools could expand the overall ability to create, edit, track, and publish not just damage assessment data and text but other documentation for the public good, individual assistance applications and beyond. New systems that better manage and visualize damage and impact data in documentation could at least relieve some of the stress of managing different user workflows via a shared platform in a time-pressed collaborative work environment that automatically coordinates the data and information matriculating up, down, and across organizational levels in the chain of command and publication, not only during and after an emergency but also in anticipation of the next one.

\section{ACKNOWLEDGMENTS}

This material was made possible by the generous input of emergency managers at the local and state levels, many thanks. Thank you also Gretchen, Hyphen, and family.

\section{REFERENCES}

[1] Henry Covey. 2019. Disaster Documentation: The Impact of Oregon's Evolving Damage Assessment Methodology for Emergency Declarations. In SIGDOC '19: Proceedings of the 37th ACM Conference on the Design of Communication, October, 04-06, 2019, Portland, OR. ACM, New York, NY, USA, 6 pages. https: //doi.org/10.1145/3328020.335393

[2] Oregon Office of Emergency Management. 2021. Damage Assessment Forms, and Templates. oregon.gov/oem/emresources/disasterassist/Pages/DamageAssessment.aspx

[3] Oregon Office of Emergency Management. 2021. Oregon Wildfire Response and Recovery Overview, including the Fires Story Map (2020 Oregon Wildfire Spotlight: Documenting impacts and support provided for the 2020 Oregon wildfire event), Damage Assessment, Sheltering and Housing, Recovery: https://experience.arcgis.com/experience/6c42bf70be214725b8dd0de8d407eca9/ ?org=geo. 
[4] April Ehrlich. 2021. Medford Launches Interactive Map To Help With Next Disaster. Jefferson Public Radio. https://www.ijpr.org/disasters-and-accidents/ 2021-05-12/medford-launches-interactive-map-to-help-with-next-disaster

[5] Sydney Dauphinais. 2021. New statewide emergency alert system on tap in Oregon. Jefferson Public Radio. https://www.opb.org/article/2021/05/04/newstatewide-emergency-alert-system-on-tap-in-oregon/

[6] Amelia Templeton. 2020. 2 people remain missing in Oregon's devastating wildfires. Oregon Public Broadcasting: https://www.opb.org/article/2020/09/24/onlytwo-people-remain-missing-in-oregons-devastating-wildfires/

[7] Federal Emergency Management Agency. 2020. Preliminary Damage Assessment Report: Oregon - Wildfires and Straight-line Winds FEMA-4562-DR (Expedited). https://www.fema.gov/sites/default/files/documents/PDAReport_ expedited_FEMA4562DR-OR.pdf

[8] Daniel Stoelb. 2021. Oregon's Wildfire Response: Lessons Learned from Our Historic 2020 Wildfire Season. Office of Emergency Management: https://oregonoem-geo.hub.arcgis.com/apps/b6dea969bf074d238cb6880995baab4d/explore; see also, Oregon Preparedness Framework Implementation Team. 2021. 2020 Oregon GIS After-Action \& Improvement Plan. 2021. OEM. https://arcg.is/0TPX981

[9] Oregon Office of Emergency Management. 2021. Hazards \& Preparedness: ShakeAlert in Oregon, How It Works. https://www.oregon.gov/oem/hazardsprep/ Pages/orshakealert.aspx

[10] Jackson County GIS. 2021. Jackson County Interactive Map (JIM). https://www.arcgis.com/apps/MapSeries/index.html?appid= fa99a30541d94b86aef4a39bc68d0580

[11] Oregon Office of Emergency Management. 2021. Oregon Damage Assessment Project. oregon-damage-assessment-project-geo.hub.arcgis.com

[12] Oregon Office of Emergency Management. 2021. Damage Assess ment Project Reference Guide. https://docs.google.com/document/d/ 1gucROhOlC5KVCBnDD0OA6cht9Sjw8xK9ueu_T-4SAYo

[13] Oregon Office of Emergency Management. 2021. Form Design Template. https://docs.google.com/spreadsheets/d/164f93_twLf1byVJyMrDwBc8_ v4XChW2VHpy6VHIxCc8

[14] Oregon Office of Emergency Management. 2021. OEM Geo Hub. oregon-oemgeo.hub.arcgis.com
[15] Kathryn Schulz. 2015. The Really Big One: An earthquake will destroy a sizable portion of the coastal Northwest. The question is when. New Yorker (July 2015); see also, Oregon Public Broadcasting. 2016. Unprepared (documentary).

[16] Erin Rose and Courtney Sherwood. 2021. 'Adjust your reality': Oregon's fire season is in full swing. Oregon Public Broadcasting. https://www.opb.org/article/ 2021/07/13/oregon-wildfire-season-bootleg-fire-roundup/

[17] Sam Stites and Jeff Thompson. 2021. Oregon enacts rules to protect workers as heat wave death toll continues to rise Oregon Public Broadcasting. https://www.opb.org/article/2021/07/06/oregon-heath-death-toll-upto-107/; see also, Shivaram. 2021. Heat Wave Killed 1 Billion Sea Creatures And Scientists Fear It Could Even Be Worse. National Public Radio. https://www.npr.org/2021/07/09/1014564664/billion-sea-creatures-musselsdead-canada-british-columbia-vancouver

[18] NPR News Now (07-17-2021 3PM EDT). https://www.npr.org/podcasts/500005/ npr-news-now

[19] National Oceanic and Atmospheric Administration. 2021. April 2021 and year to date were among Earth's top-10 warmest. U.S. Department of Commerce. https://www.noaa.gov/news/april-2021-and-year-to-date-were-amongearth-s-top-10-warmest; National Public Radio. 2021. Concerns About Variants, Pandemic Politics, Western Wildfires. Up First (podcast). https://www.npr.org/ podcasts/510318/up-first; Intergovernmental Panel on Climate Change. (2021): Climate change widespread, rapid, and intensifying. IPCC Report (press release August 8, 2021). https://www.ipcc.ch/2021/08/09/ar6-wg1-20210809-pr/

[20] Benjamin H. Strauss, Philip M. Orton, Klaus Bittermann, Maya K. Buchanan, Daniel M. Gilford, Robert E. Kopp, Scott Kulp, Chris Massey, Hans de Moel, Sergey Vinogradov. 2021. Economic damages from Hurricane Sandy attributable to sea level rise caused by anthropogenic climate change. Nature Communications. https://doi.org/10.1038/s41467-021-22838-1.

[21] April Ehrlich. 2021. FEMA denied most Oregonians' requests for wildfire disaster assistance. Jefferson Public Radio. https://www.opb.org/article/2021/02/11/ oregon-2020-wildfires-fema-disaster-aid-denied/

[22] Bruno Latour. 2005. Reassembling the Social. New York: Oxford University Press 